\title{
STRATEGI DAN USAHA RESERVASI UNTUK MENINGKATKAN TINGKAT HUNIAN DI GRAND ORCHID HOTEL YOGYAKARTA
}

\author{
Hery Krestanto \\ NIDN 0507128001 \\ Dosen Akademi Pariwisata Yogyakarta \\ Email: herychrestanto@gmail.com
}

Histori Artikel

Submitted:

1 April 2019

Reviewed:

25 April 2019

Accepted:

29 April 2019

Published:

15 Mei 2019

\section{ABSTRACT}

This study aims to determine the strategy and reservation effort to increase occupancy rates at the Grand Orchid Hotel Yogyakarta. This research was conducted at the Grand Orchid Hotel in Yogyakarta. The type of data collected in this study is qualitative, namely the strategy and reservation effort to increase occupancy rates at the Grand Orchid Hotel Yogyakarta. The data analysis technique used is the direct observation method, direct interview. The results of the research obtained are that reservations have a very important role to increase occupancy rates and there are things that support to increase occupancy rates are complete room facilities, strategic hotel location, intensity of promotion, good employee service.

Keywords: Reservation, Strategy, Occupancy Rate

\section{PENDAHULUAN}

Perkembangan dunia pariwisata dewasa ini cukup baik, Era globalisasi ini menuntut semua pihak untuk bersaing memperebutkan kedudukan sebagai penentu sektor pariwisata, dalam hal ini dituntut mengembangkan segala macam aspek. Pariwisata merupakan salah satu segi aspek yang harus dikembangkan, karena mempunyai nilai integritas tinggi dalam menentukan kemajuan zaman. Industri pariwisata sangat erat kaitannya dengan dunia perhotelan karena hotel bergerak dalam bidang pelayanan jasa beserta akomodasinya untuk mendukung lancarnya pariwisata di Indonesia (Agus Sulastiyono, 2016)

Pariwisata mempunyai arti rangkaian kegiatan yang berhubungan dengan perjalanan untuk rekreasi, pelancong, dan tourism. Pariwisata adalah tourism yang merupakan kegiatan perjalanan seseorang individu dari tempat tinggal asalnya ke suatu tempat di kota lain ataupun negara lain dalam waktu tertentu dengan tujuan bersenangsenang (I Gede Pitana, 2009).
Menurut Surat Keputusan Menparpostel No. KM/37/PW/304/MPPT-86 Hotel adalah seluruh jenis akomodasi yang mempergunakan sebagian atau seluruh bangunan untuk menyiapkan jasa penginapan, makanan, dan minuman serta jasa penunjang lainya bagi umum yang dikelola secara komersial.

\section{LITERATURE REVIEW \\ Pengertian hotel}

Hotel adalah suatu industri atau usaha jasa yang dikelola secara komersial (Hermawan dkk., 2018). Sedangkan pengertian Hotel menurut SK Menparpostel No. KM/37/PW/304/MPPT-86 adalah suatu jenis akomodasi yang menyediakan sebagian atau seluruh bangunan untuk menyediakan jasa penginapan, makanan dan minuman serta jasa lainnya bagi umum, yang dikelola secara komersial.

Dari pengertian diatas dapat disimpulkan bahwa hotel adalah :

1. Merupakan jenis akomodasi.

2. Menyediakan pelayanan akomodasi, makanan dan minuman. 
3. Disediakan bagi setiap orang.

4. Dikelola secara komersial (bertujuan untuk mencari keuntungan).

\section{Klasifikasi Hotel:}

Hotel dapat di klasifikasikan menjadi 8 katagori (Bagyono,2012) yaitu:

Berdasarkan Penentuan Komponen Harga Kamar:

1. European Plan (E.P)adalah hotel dimana harga yang telah ditetapkan terdiri dari harga kamar saja.

2. Continental Plan (C.P)adalah hotel dimana harga yang telah ditetapkan terdiri dari harga kamar termasuk breakfast.

3. Modified American Plan (M.A.P)adalah hotel dimana harga yang telah ditetapkan terdiri dari harga kamar termasuk satu kali lunch atau satu kali dinner.

4. Full American Plan (F.A.P)adalah hotel dimana harga yang telah ditetapkan terdiri dari harga kamar termasuk tiga kali makan (breakfast, lunch, dinner).

Berdasarkan Lokasi

1. Mountain Hotel adalah hotel yang terletak di daerah pegunungan.

2. Beach Hotel Adalah hotel yang terletak di tepi pantai.

3. Highway hotel adalah hotel yang terletak di tepi jalan bebas hambatan dan biasanya diantara dua kota.

4. Airport Hotel adalah hotel yang terletak tidak jauh dari airport.

5. Resort Hotel adalah hotel yang berlokasi di kawasan wisata.

6. City Hotel adalah hotel yang berlokasi di perkotaan.

Berdasarkan lama buka dalam setahun

1. Seasonal Hotel adalah hotel yang hanya buka pada waktu- waktu tertententu dalam setahun ( 3 bulan, 6 bulan, 9 bulan )

2. Year Round Hotel adalah hotel yang buka sepanjang tahun.

Berdasarkan luas dan jumlah kamar :

1. Hotel kecil (small hotel) adalah hotel yang mempunyai 25 kamar atau kurang.

2. Hotel sedang (average hotel) adalah hotel yang mempunyai lebih dari 25 kamar dan kurang dari 100 kamar.
3. Hotel menengah (above average hotel) adalah hotel yang mempunyai lebih dari 100 kamar dan kurang dari 300 kamar.

4. Hotel besar (large hotel) adalah hotel yang mempunyai lebih dari 300 kamar.

Berdasarkan Tarif Kamar

1. Economy Class Hotel adalah hotel yang memiliki tarif kamar kelas ekonomi ( harga kamar lebih murah)

2. First Class Hotel adalah hotel dengan tarif kamar mahal

3. Deluxe / luxury Hotel adalah hotel yang memiliki harga kamar sangat mahal.

Berdasarkan Lama Tamu Menginap

1. Transient Hotel adalah hotel dimana para tamunya menginap hanya untuk satu atau dua malam.

2. Semi Residential Hotel adalah hotel dimana para tamunya menginap lebih dari dua malam sampai satu minggu.

3. Residential Hotel adalah hotel dimana para tamunya menginap untuk jangka waktu lama, lebih dari satu minggu.

Berdasarkan jenis tamu yang menginap :

1. Hotel keluarga (family hotel) adalah hotel yang dirancang untuk keluarga.

2. Hotel bisnis (business hotel) adalah hotel yang dirancang untuk para usahawan.

3. Hotel wisatawan (tourist hotel) adalah hotel yang dirancang untuk wisatawan.

4. Hotel transit (transit hotel) adalah hotel yang dirancang untuk orang - orang yang melakukan persinggahan sementara dalam suatu perjalanan.

5. Hotel perawatan kesehatan (cure hotel) adalah hotel yang dirancang untuk orang orang yang menginginkan penyembuhan penyakit atau meningkatkan kesehatannya.

6. Hotel konvensi (convention hotel) adalah hotel yang dirancang untuk penyelenggaraan konvensi atau perjamuan.

Berdasarkan Aktivitas:

1. Hotel adalah suatu jenis akomadasi yang menggunakan sebagian atau seluruh bangunannya untuk penginapan dan menyediakan makanan dan minum serta jasa lainya bagi umum yang dikelola secara komersial. 
2. Motel adalah bangunan yang terletak di pusat kota dan daerah dekat jalan raya (highway) disediakan dalam bentuk apartment dan dapat untuk tempat tinggal kurang dari 24 jam dan apartment tersebut memiliki pintu masuk tersendiri dan satu garasi, juga terdapat fasilitas bengkel perbaikan dan pencucian mobil serta pom bensin.

3. Losmen atau Penginapan (Lodgements) adalah suatu usaha komersial yang digunakan untuk penginapan saja.

4. Pondok Remaja (Youth Hostel) adalah suatu usaha yang tidak bertujuan komersial yang menggunakan seluruh atau sebagian dari bangunan untuk memperoleh pelayanan penginapan satu lainnya. Fasilitas yang ada di pondok remaja adalah:

a) Menyediakan kamar tidur biasanya diisi oleh lebih dari 2 orang per kamar dengan harga murah.

b) Menyediakan makanan, minuman dan barang - barang keperluan sehari - hari.

c) Dirancang untuk kaum muda dan biasanya para murid -murid sekolah, pelajar dan mahasiswa yang sedang melakukan study tour, kunjungan dan yang lainnya.

5. Bumi Perkemahan (Camping Ground)

Menyediakan tempat yang luas untuk fasilitas perkemahan sebagai ruang tidur.

Ruang perkemahan tersebut biasanya disewakan oleh pemiliknya termasuk air bersih, sanitasi dan keperluan masak.

6. Pondok Wisata atau Wisma (Homestay atau Guest House) Jenis usaha akomodasi perorangan yang berasal dari rumah penduduk dengan menggunakan sebagian rumahnya untuk penginapan dengan perhitungan sewa harian dan biasanya terletak di daerah wisata.

7. Inn adalah suatu akomodasi yang disediakan untuk penginapan dan juga untuk pelayanan makan dan minum bagi orang-orang yang singgah sementara waktu.

8. Bungalow adalah sejenis akomodasi yang berbentuk rumah, berlokasi dekat pengunungan atau jauh dari kota.
Disewakan untuk keluarga sebagai tempat istirahat.

9. Cottage adalah sejenis akomodasi yang terletak di pinggir pantai atau danau dan letaknya terpisah, disewakan untuk keluarga dan dilengkapi fasilitas lengkap (rekreasi).

10. Ryokan adalah penginapan ala jepang yang khas menurut adat istiadat negeri tersebut. Perlengkapan serta pelayanannya disesuaikan dengan tata cara jepang.

11. Holiday Flat adalah jenis akomodasi seperti rumah susun dan disewakan secara mingguan ditambah pelayanan breakfastsetiap hari dan kebersihan kamar hanya dikerjakan pada pagi hari saja kecuali ada permintaan dari tamu.

12. Holiday Camp adalah bentuk akomodasi dimana pelayanan yang ditawarkan merupakan paket hiburan termasuk harga kamar, makan, minum dan fasilitas olahraga.

13. Floating Hotel (Hotel Terapung) atau Marine Hotel atau kapal pesiar adalah hotel atau kapal yang mewah dengan fasilitas sebagaimana layaknya bintang lima.

14. Chalet adalah bentuk akomodasi yang terbuat dari bahan kayu dan terdapat disepanjang lereng gunung (berasal dari Switzerland).

\section{ProdukHotel:}

Produk hotel terdiri dari produk nyata (tangible product), produk yang dapat dilihat oleh tamu misalnya: kamar, makanan, minuman dan fasilitas lain yang ada di hotel tersebut dan produk tidak nyata (intangible product), produk yang tidak dapat dilihat langsung tetapi dapat dirasakan oleh tamu dan untuk memperolehnya tamu harus membayar seperti :

1. Pelayanan untuk tamu

2. Keamanan dan kebersihan

3. Keramah - tamahan (Bagyono, 2012)

\section{Pengertian Strategi}

Strategi adalah rute yang dibutuhkan agar sampai pada tempat tujuan. Strategi merupakan cara meningkatkan usaha dari 
satu tingkat yang lebih rendah ke tingkat selanjutnya dan menentukan arah, memberi motivasi, membimbing, mulai awal sampai akhir ( Grade, 2008)

\section{Pengertian Reservasi}

Reservasi adalah satu seksi pada departement kantor depan yang tugas dan tanggung jawabnya menangani permintaan pemesanan dari para calon tamu (Bagyono, 2016)

Sebelum memutuskan bahwa reservasi diterima, petugas perlu memeriksa tersedia atau tidaknya kamar yang diinginkan oleh calon tamu. Cara menentukan ketersediaan kamar (Bagyono, 2016)antara lain :

\section{Forecast Board}

Desain dan isi papan forecast pada dasarnya sama dengan kalender yang biasanya digantung di dinding dekat dengan petugas reservasi agar dapat dengan mudah melihat informasi pada papan ketika dibutuhkan untuk menjawab permintaan tamu. Papan ini umumnya ditulis untuk periode 4 bulan dan tanggal yang tercantum menunjukkan informasi status kamar. Apabila tidak ada tanggal yang diberi bulatan hitam berarti semua kamar dapat dipesan. Papan forecast diperbaharui secara regular. Reservation Diary adalah buku yang digunakan oleh petugas reservasi untuk memasukkan data-data pemesanan seperti nomor kamar, jenis kamar, nama tamu dan alat. Jam datang dan jam berangkat, harga kamar serta permintaan khusus.

2. Reservation Chart (Booking Chart)

Reservation chart adalah bagian reservasi yang digunakan untuk melihat tersedia atau tidaknya kamar yang dipesan oleh tamu. Bagan reservasi dibedakan menjadi dua jenis, yaitu conventional chart dan density chart. Bagan reservasi konvcensional cocok digunakan di hotel kecil dimana jumlah kamar yang dimiliki cukup terbatas. Sedangkan density chart (wall chart) lebih cocok dipakai di hotel besar yang memiliki banyak kamar. Ciri dari bagan konvensional adalah semua nomor kamar dicantumkam, lengkap jenis tempat tidurnya. Pengisiannya adalah nama keluarga tamu ditulis di atas garis panah dengan menggunakan pensil. Bagan ini dibuat dengan basis bulanan. Sedangkan pada density chart tidak dicantumkannomor kamar dan nama tamu tidak ditulis pada bagan. Bagan ini dibuat dalam satu halaman degan basis harian dan berdasarkan jenis tempat tidur. Cara pengisiannya adalah menggunakan pen dimulai dari jumlah kamar yang tersedia dari jumlah angka terbesar sampai yang terkecil, sehingga dapat diketahui jumlah kamar yang masih bisa dipesan hari itu. Ada yang menggunakan garis miring dan ada pula tanda silang.

3. Computerized System

Hotel-hotel yang menggunakan sistem informasi perhotelan (Information System / Property Management System / Electronic Data System), akan mendapatkan kemudahan-kemudahan dalam mengakses data. Contohnya adalah apabila petugas ingin mengetahui posisi kamar-kamar yang masih bisa dipesan maka dengan hanya menekan tombol tertentu semua data kamar yang tersedia akan muncul di layar dengan cepat. Demikian juga apabila petugas menginginkan jenis kamar tertentu yang muncul maka dengan mengetik tombol tertentu kamar dimaksud akan muncul. Pada menu "Room Availability" dapat diketahui statistik 1 kamar untuk masa yang akan datang.

\section{Reservation Network System}

Ada 2 macam sistem jaringan reservasi yang biasa digunakan oleh hotel (Bagyono, 2016)antara lain :

1. Anffiliate Reservation Networkadalah sistem reservasi hotel dimana hotel-hotel yang masuk dalam hotel chain turut saling mengirim reservasi,artinya bahwa tamu dapat mengadakan reservasi hotel yang diinginkan melalui hotel yang masih masuk dalam satu grup,manfaatnya bagi hotel adalah mengurangi biaya reservasi sekaligus mempopulerkan nama hotel. 
2. Non Affiliate Reservation Network adalah sistem reservasi hotel independen (bukan hotel chain) yang menyewa sistem jaringan reservasi untuk disambungkan ke jaringan reservasi secara nasionalmaupun internasional agar hotel yang bersangkutan mendapatkan permintaan reservasi dari hotel lain yang masuk dalam jaringan tersebut.

\section{Type of Room Rate}

Ada berbagai tipe harga yang diberikan kepada tamu saat tamu akan menginap di hotel, Adapun tipe - tipe harga tersebut (Bagyono, 2016)antara lain:

1. Publish rate adalah harga umum

2. Package rate adalah harga paket (termasuk breakfast)

3. Company rate adalah harga khusus yang diberikan oleh perusahaan

4. Airline rate adalah harga khusus yang diberikan oleh maskapai penerbangan.

5. Goverment rate adalah harga khusus untuk pegawai pemerintah

6. Travel agent rate adalah harga khusus yang diberikan travel agent atau biro perjalanan.

7. Family rate adalah harga khusus yang diberikan pada hari jum'at sampai minggu khususnya untuk keluarga.

8. Weeken rate adalah harga khusus yang diberikan pada saat hari jum'atsampai minggu untuk umum.

9. Day use rate adalah harga khusus yang diberikan untuk tamu yang tinggalbeberapa jam saja.

10. Over flow rate adalah harga khusus yang diberikan untuk tamu karenahotel mengalami full book sehingga dipindah ke hotel lain.

11. Flat rate adalah harga khusus yang diberikan ke tamu untuk tipe kamaryang berbeda.

12. Group rate adalah harga khusus yang diberikan untuk tamu rombongan(minimal 15 kamar).
13. Seasonal rate adalah harga kamar yang diberikan pada saat hari besar(natal, lebaran dan tahun baru).

\section{Standar Operasional Prosedure dalam Reservation}

Dalam penanganan reservasi kamar seorang reservation staff haruslah mengikuti prosedur atau standar yang telah ditetapkan, karena dalam penanganan reservasi kamar tidak bisa dilakukan hanya dengan asal asalan saja yang penting mengerti, tetapi harus sesuai standar bahkan harus dengan courtesy yang baik pula. Keadaan yang demikian itu dapat merugikan pihak hotel, selain pendapatan hotel menurun, tidak akan adanya peningkatan jumlah tamu yangmenginap di hotel. Oleh karena itu seorang reservation staff dalam penanganan reservasi kamar haruslah selalu menggunakan pedoman atau standar yang telah ditentukan.

Standar operasional prosedure adalah acuan kerja yang dapat dijadikan standar dalam bekerja di semua department yang ada di suatu perusahaan sehingga pekerjaan dapat diselesaikan dengan baik, cepat, tepat, efektif dan efisien. Dalam standar operasional prosedure tertuang prosedur apa saja yang harus dilakukan, tugas, wewenang dan tanggung jawab masing - masing bagian sudah dibakukan, sehingga ketika ada atau tidak ada kesalahan sistem yang keluar dari jalurnya akan bisa di identifikasi, selain itu juga standar operasional prosedure juga dapat dijadikan salah satu alat untuk menilai kinerja organisasi atau karyawan. Adapun manfaat dari standar operasional prosedure adalah:

1. Dapat menjaga konsistensi dalam menjalankan suatu prosedur kerja.

2. Lebih jelas mengetahui peran dan posisi masing-masing di internal perusahaan.

3. Memberikan kejelasan mengenai prosedur kerja dan tanggung jawab dalam proses terkait.

4. Memberikan keterangan mengenai keterkaitan dengan satu proses kerja dengan proses kerja. 
5. Meminimalisir kesalahan dalam melakukan pekerjaan.

6. Membantu dalam melakukan evaluasi terhadap setiap proses operasional perusahaan

Langkah - langkah standar oprasional prosedure reservation adalah:

\section{Formulir pemesanan kamar}

Setiap pemesanan kamar yang diterima melalui alat komunikasi apa saja, dan sumber dari mana saja, dicatat dalam formulir pemesanankamar / reservation card,formulir ini berguna untuk memastikan bahwa semua informasi yang diperlukan sudah diperoleh, dan untuk memudahkan dalam pemesanan data dan untuk memudahkan hal-hal yang penting buat tamu, seperti pembayaran,harga kamar, waktu tiba, keuntungan lain adalah untuk menghindari hilangnya data tamu.

Untuk memudahkan penanganan pemesanan

kamar dana penerimaan tamu, maka reservation card dibuat dengan beberapa warna, misalnya:

- Warna putih : untuk tamu perorangan dan perusahaan / kantor.

- Warna kuning : untuk tamu dari biro perjalanan.

- Warna hijau : untuk tamu penting.

\section{Cara Pengisian Reservation Card}

Cara pengisian formulir ini sangat mudah dengan mengikuti prosedur yangtelah ditentukan yaitu mengetahui cara-cara menuliskan nama tamu yang akan menginap dengan sistim ejaan,setelah mengetahui bahwa pemesanan kamar dapat diterima maka mulai mencatat atau mengisi formulir sebagai berikut:

a. Nama tamu yang akan menginap dicatat dengan lengkap.

b. Tanggal kedatangan tamu disertai nomor pesawat dan jam kedatangan

c. Nama kota tempat tinggal terakhir tamu.

d. Tanggal keberangkatan tamu

e. Jumlah tamu yang akan menginap

f. Harga kamar per malam

g. Jenis kamar yang dipesan.

h. Namapemesan

i. Nomor telepon pemesan

\section{Prosedur Pemesanan Kamar :}

Tata cara pemesanan melalui telepon :

a. Telepon diterima kemudian dijawab dengan tepat.

b. Pertama-tama disambut dengan úcapan greeting "good morning hotel grand orchid yogyakarta, reservation speaking, may I help you.

c. Tanyakan nama tamu yang akan menginap, tanggal berapa tiba, dan tanggal berapa berangkat serta jumlah dan tipe kamar.

d. Lihatlah keadaan kamar pada table atau pada laporan dan tamu diminta untuk menunggu sebentar.

Apabila permaintaan tamu telah dipenuhi, berikan informasi tipe kamar, harga kamar,dan apabila perlu dimintakan uang muka (deposit).

f. Isilah formulir pemesanan kamar dengan lengkap.

g. Ulangi seluruh permintan tamu untukmenghindari salah catat.

h. Sampaikan ucapan terima kasih atas pemesanan kamarnya kepada yangbersangkutan.

\section{Konfirmasi Kembali (Reconfirmation)}

Kofirmasi dilaksanakan pada saat tiga hari sebelum tanggal kedatangan tamu, untuk tamu rombongan konfirmasi dilaksanakan seminggu sebelum datang dan dua hari sebelum rombongan tersebut datang, hal ini untuk menghindari perubahan atau pembatalan mendadak,reconfirmation dapat dilaksanakan dengan melaui telepon atau facsimile, seorang reservation staff dituntut untuk memiliki kualifikasi:

a. Menguasai dan hafal jenis kamar beserta fasilitas yang ada didalamnya, syarat mutlak bagi mereka yang ingin dipanggil menjadi reservation staff adalah benar benar mengetahui jenis kamar beserta 
fasilitas yang ada, dalam operasionalnya, reservation staff dituntut untuk memberikan kepuasan pada tamu dengan cara memberikan pelayanan yang maksimal, sehinggamembuat tamu merasa bangga dan terhormat.

b. Mempunyai ketrampilan dan skill yang baik.

Ketrampilan disini tidak hanya sekedar ketrampilan saja, tetapi lebih dari itu seorang reservation staff juga harus trampil dalam berbicara dan menulis bahasa inggris atau bahasa yang lainnya, penampilan rapi dan teratur, kepribadian yang ramah, mempunyai minat yang tinggi dalam bekerja untuk melayani tamu, kecerdasan dan ketetapan dalam menjalankan prosedur yang telah ditetapkan.

\section{METODE PENELITIAN}

Metode penelitian tentang strategi reservasi untuk meningkatkan tingkat hunian menggunakan penelitian deskriptif kualitatif. Teknik pengumpulan data bersumber dari data primer yang merupakan informasi yang diperoleh dari sumber- sumber primer (Sugiyono, 2017)

1. Pengamatan langsung ( direct observation)

2. Metode observasi yaitu cara memperoleh data yang dilakukan dengan cara mengamati dan mencatat secara secara langsung gejala- gejala yang diteliti. Penulis mendatangi langsung Hotel Grand Orchid Yogyakarta

3. Wawancara langsung (direct Interview)

4. Metode Wawancara adalah proses tanya jawab dalam penelitian yang berlangsung secara lisan. Penulis melakukan wawancara terhadap pihak yang terkait yaitu staf reservasi Hotel Grand Orchid Yogyakarta

5. Dokumentasi ( Documentation )

6. Dokumentasi ini dilakukan guna mendapatkan foto atau gambar Hotel Grand Orchid Yogyakarta.

\section{PEMBAHASAAN}

Dalam menghadapi era (globalisasi) dimana dirasakan semakin ketatnya persaingan usaha perhotelan. maka dibutuhkan suatu strategi usaha yang dapat digunakan untuk menguasai pasar dan meningkatkan penjualan. Strategi mempunyai arti suatu rencana yang diutamakan untuk mencapai tujuan perusahaan yang menganut pada konsep pemasaran yang memberikan kepuasan kepada tamu atau masyarakat lain dalam pertukarannya untuk mendapatkan laba.

Strategi ini haruslah diatur sedemikian rupa sehingga akan dapat berfungsi sebagai senjata yang tepat dalam melawan pesaing pesaingnya, oleh karena itu senjata yang paling tepat tersebut harus disesuaikan dengan keadaan pasar serta kondisi persaingan yang akan dihadapi. Strategi yang digunakan dalam meningkatkan tingkat hunian adalah:

\section{Pendekatan}

Seorang petugas penerima tamu harus selalu melakukan pendekatan kepada para tamu dengan cara menyambut tamu yang datang dengan ramah tamah, sopan, senyum. Langkah pendekatan ini berrnaksud untuk mendapatkan kesan pertama (first impression) yang baik dari tamu.

2. Penjelasan dan Penetapan Harga Kamar (Presentation and Pricing)

Bagi tamu yang baru pertama kali menginap di hotel anda, jelaskan terlebih dahulu tentang keadaan kamar yang ada seperti letak/lokasi kamar, keuntungan yang dapat diperoleh bila menginap kamar tersebut. Dengan menjelaskan fasilitasfasilitas yang terdapat di kamar secara lengkap maka bila diajukan harganya diharapkan tamu tidak akan terkejut karena mungkin terlalu mahal. Dalam menawarkan kamar mulailah dengan harga kamar yang tertinggi, bila tamu merasa keberatan karena terlalu mahal maka tawarkankamar yang harganya setingkat lebih rendah, demikian seterusnya sampai harga kamar yang termurah.

3. Mengatasi tamu yang merasa keberatan (Handling Objection) 
Adalah membantu untuk menentukan kamar mana yang sebaiknya dipilih oleh tamu.

4. Memberikan potongan harga atau harga spesial untuk hari - hari tertentu.

5. Selalu berusaha meningkatkan penjualan kamar dengan cara memberikan sebanyak - banyaknya informasi kepada tamu tentang jenis - jenis kamar beserta fasilitas yang ada didalamnya.

6. Mengetahui dengan baik mengenai jenis jenis kamar yang akan dijual, sehingga bila ada calon tamu mengajukan beberapa pertanyaan setiap keraguan dapat dijawab dengan efektif dan efisien

7. Menyakinkan tamu bahwa kenyamanan dan jasa pelayanan yang memuaskan akan didapatkan ketika menginap

Selain strategi diatas untuk meningkatkan tingkat hunian dapat dilakukan dengan analisis SWOT ( Prasetyo dkk., 2018) yaitu :

1. Strength / kekuatan yang dimiliki Hotel Grand Orchid antara lain:

a. Kelengkapan fasilitas kamar

Kelengkapan fasilitas kamar seperti tempat tidur, bantal, bed cover, TV, air panas, AC,Alamari dan telepon.

b. Lokasi hotel strategis

Lokasi hotel strategis dekat dengan bandara

c. Intensitas promosi

Intesitas promosi yang digunakan melakukan kerja sama dengan travel agent lokal maupun travel agent nasional.

d. Pelayanan Karyawan yang baik

Pelayanan yang baik sangat berpengaruh bagi kelangsungan hidup perusahaan, dengan pelayanan yang memuaskan pelanggan akan loyal terhadap hotel.

2. Weakness (Kelemahan)

a. Terbatasnya lahan parkir

b. Terbatasnya ruang meeting

3. Oppotunity (peluang)

a. Teknologi reservasi yang digunakan online

b. Stabilitas keamanan kondusif

c. Kenyamanan

4. Threat (ancaman) a. Adanya tawar menawar dan persaingan harga

b. Banyaknya usaha sejenis hotel

\section{KESIMPULAN}

Berdasarkankan hasil penelitian dan pembahasan dapat disimpulkan sebagai berikut: Reservasi mempunyai peranan yang penting untuk meningkatkan tingkat hunian. Hal-hal yang medukung untuk meningkatkan tingkat hunian adalah kelengkapan fasilitas kamar, letak hotel yang strategis, intensitas promosi, pelayanan karyawan yang baik.

\section{DAFTAR PUSTAKA}

T.Prasetyo Hadi Atmoko dan Heni Widyaningsih. 2018. Manajemen dan Bisnis Perhotelan. Yogyakarta: Explore.

Sugiyono, 2017. Metode Penelitian Kualitatif. Bandung : Alfabeta.

Bagyono, 2016. Teori dan Praktik Hotel Front Office. Bandung : Alfabeta

Grade, R, 2008. Strategi Ampuh Berbisnis. Yogyakarta : B-First.

Hermawan, H., Brahmanto, E dan Faizal H. 2018. Pengantar Manajemen Hospitality. Pekalongan: Penerbit NEM.

Bagyono. 2012. Pariwisata \& Perhotelan. Bandung : Alfabeta

I Gede Pitana dan I ketut Surya Diarta. 2009. Pengantari Ilmu

Pariwisata. Yogyakarta: Penerbit Andi

Agus Sulastiyono. 2016. Manajemen Penyelengaraan Hotel. Bandung : Alfabeta 